\title{
Correlation as a Means of Expressing Syntactic Connections of Parenthetical Construction with Main Sentence
}

\author{
Marine Yaghubyan \\ Yerevan State University
}

\begin{abstract}
Parenthetical constructions are connected with the sentence by means of a special type of grammatical connection - correlation. The characteristic feature of this type of grammatical connection is that between the parenthetical construction and the sentence there exists a lexical connection, the grammatical expression of which is the insertion of parenthetical constructions within the sentence structure. The specific character of this type of grammatical connection is that parenthetical construction is independent of the sentence part it defines and has an independent grammatical shaping. The special type of the connection of parenthetical construction with the main sentence distinguishes the parenthetical construction from the part of the sentence which depends on its head-word. Correlation shapes the syntactic isolation of parenthetical constructions within the sentence. It is one of the main features of parenthetical construction as an independent syntactic category.
\end{abstract}

Key words: Correlation, parenthetical construction, grammatical connection, semantic connection, agreement, governınent, enclosure, correlative connection, upsetting, syntactic isolation.

\section{Introduction}

A sentence is a linear consequence that is characterized by the definitely organized semantic patterns. Different words and constructions appear in the sentence creating structural and mental unity between parts of sentences and between sentences making up the text. A sentence is a unit of speech whose grammatical structure conforms to the laws of the language and which serves as the chief means of conveying a thought. It is not only a means of communicating something about reality but also a means of showing the speaker's attitude to it.

In a sentence the principal parts, secondary parts and independent elements can be distinguished. Sometimes the construction of English sentences does not follow the rules accepted by the normative grammar. Very often we observe different kinds of upsettings in a sentence. In our speech there is a great variety of phenomena which make it "nonsmooth". All these phenomena may be united under the name of parenthetical constructions $-i$. e. elements which syntactically and semantically are sccondary, additional to the main discourse. The term parenthetical construction embraces a great variety of syntactic phenomena - from pauses to lengthy parenthetical interpolations. In general, parentheticals are expressions that are linearly represented in a given string of utterance, but seem structurally independent at the same time. 
Parentheticals are constructions that provide less important or background information in texts and they are a prime example of interactions between referring expressions, syntax, layout and discourse structure. They help readers distinguish between more and less important propositions, and therefore significantly increase the fluency and readability of the generated text. No question can be put to it.

The difficulty in the study of parenthetical constructions is also complicated by the following reason: it is a well-established fact that the syntactic organization of the sentence in the Indo-European languages is fully based on the connection of words with the help of morphological markers.

\section{The Special Status of the Parenthetical Construction in the Sentence}

The main ways of syntactic bond realization between words in the English language are agreement, government, parataxis, joining by means of connective words, enclosure (Yartseva 1961:23). All these grammatical means of word connection, from which the essential part belongs to parataxis, act within word-combinations (Jigadlo et. al. 1956:237) which are components of the sentence.

The parenthetical construction does not form a word-combination with the word defined, consequently, it is not connected with the latter with the help of any of the grammatical means of connection stated above.

As parenthetical construction does not form a word-combination with a part of the sentence, it is possible to speak only about such a grammatical connection which is realized not in a word-combination, but in a sentence. The usual means of word connection in the English language are intonation and word order, that is, the parts of a sentence have definite places which give them grammatical and not infrequently lexical meaning, and they (the parts of a sentence) are inserted in the sentence with the intonation which fulfills the function of connection (Alexandrova 2007).

As it was stated above, the phonetic peculiarities and the position of parenthetical constructions distinguish the latter from the parts of a sentence. Hence, the grammatical connection of parenthetical construction with the sentence (this connection is beyond doubt, as in the sentence, which is a communicative unit of speech, there cannot be alien linguistic units) is to have specific peculiarities and features.

The analysis of the material has shown that the grammatical connection of parenthetical construction with main sentence is a special correlative connection. According to A. Rudnev "correlation is a semantic connection which is grammatically expressed by the fact of inserting the defining words in the structure of the sentence in the neighbourhood with the words they define. But as different from other types of connection, in correlative connection the defining words acquire their own shaping irrespective of the defined words in the sentence" (Rudnev1959:123).

Parenthetical constructions meet the requirements of the correlative connection.

The semantic connection of parenthetical constructions with the sentence is observed in absolutely all the cases. It is enough to point out the common features of the numerous lexical and lexico-semantic connectives characteristic of the overwhelming majority of parenthetical constructions to prove the tangibility of this semantic connection. 
Thanks to this semantic connection with the sentence the parenthetical construction is inserted into it, first of all into the intonation pattern of the sentence as a whole which gives it the opportunity to take part in the communicative function typical of the given sentence. Nevertheless, being phonetically singled out it is not considered to be a part of the sentence.

The special status of the parenthetical construction in the sentence is also confirmed by its grammatical shaping which is independent of the word it defines. This is manifested in violating the means of syntactic bond in an English word-combination, namely

1. There is no agreement between the correlated words, for example:

(1) I have taken a few notes in my poor way, of some of that man's proceedings - my adopted brother, sir - which would amaze you.

(Ch. Dickens "Martin Chuzzlewit" p.77)

In this case the correlated elements are man's - brother, i. e. the noun in the main sentence is in the possessive case and in the parenthetical construction - in the common case.

(2) Oh, they have their 'tarts' they've all got a girl's 'photo in their paybooks - and what girls! (R. Aldington "Death of a Hero" p.270)

The correlated ones are girl's - girls, that is, the noun in the possessive case, singular and the noun in plural.

2. In the parenthetical construction the rules of the use of functional words are not observed either, thus resulting in their specific grammatical shaping. Thus in the parenthetical construction consisting of word-combination "noun + attribute", expressed by an adjective, the article can be missing, for instance:

(1) And the lawyer - foul brute - had unsympathetically said that George's possessions ought to be given to his wife ...

(R. Aldington "Death of a Hero" p.37)

(2) ... and how she knew Mr. Brumley (naughty man) meant to refiuse to give her autographed copies...

(H.G. Wells "Sir Isaak Harmon's Wife" p.41)

The article can also be missing in the word-combinations of this type which refer to the whole sentence, for instance:

(1) ... orif it were the husband who died - unpleasant thought - threw herself on his body in an agony of remorse.

(J. Galsworthy "Man of Property" p.76) 
3. In the parenthetical construction the preposition can be omitted. This in other types of constructions, i. e. not of the parenthetical type, is not possible, for example:

(1) Renwick took the paper and, perceiving that it was a translation of Latin prose - Cicero, probably, he imagined - written in a smooth yet unformed hand, he began to read ...

(A. Cronin "Hatter's Castle" p.603)

In the parenthetical construction the preposition is omitted before the word Cicero. Let's compare with the sentence:

\section{Other translations of poems of Rabindranath Tagore by Aurobindo Rose... \\ (R. Aldington "Death of a Hero" p.59)}

Here, in a similar situation, but not in the parenthetical construction, the preposition "or" is present.

IV. The parenthetical construction can belong to a different sentence type as compared to the main sentence. This fact once again emphasizes the independence of parenthetical constructions. For instance:

(1) ...hut his relations were against the match; Ana - what do you think? -he and Miss Georgiana made it up to run away ...

(Ch. Bronte "Jane Eyre" p.121)

(2) But, Miss Summerson! Angel! - No, don't ring - I have been brought up ... (Ch. Dickens "Martin Chuzzlewit" p.134)

(3) ... she came with me over the sea in a great ship with a chinney that smoked - how it did smokel - and I was sick.

(Ch. Bronte "Jane Eyre" p.134)

In all three cases the main sentence is a declarative sentence, but the parenthetical sentences are interrogative (1), imperative (2), exclamatory (3) in respective examples.

\section{Conclusion}

The analysis of the grammatical connection of the parenthetical constructions with the rest of the sentence allows us to come to the following conclusions:

1. Parenthetical constructions are connected with the sentence by means of a special type of the grammatical connection - correlation. The characteristic feature of this type of grammatical connection is that between the parenthetical construction and the sentence there exist a lexical connection, the grammatical expression of which is the insertion of parenthetical constructions within the sentence structure. The specific character of this type of the grammatical connection is that the parenthetical construc- 
tion is independent of the sentence part it defines and has an independent grammatical shaping.

2. The special type of the connection of the parenthetical construction with the main sentence, distinguishes the parenthetical construction from the part of the sentence, which depends on its head-word.

3. Correlation, the grammatical connection established between the parenthetical constructions and the rest of the sentence, shapes the syntactic isolation of the parenthetical constructions within the sentence. It is one of the main features of the parenthetical constructions as an independent syntactic category.

\section{References:}

1. Alexandrova, O.V.; Komova, T.A. (2007) Modern English Grammar: Morphologv and Syntax. M.: Academia.

2. Alexandrova, O.V. (1984) Problemy expresivnogo sintaksisa. M.: Vysšaja Śkola.

3. Blakemore, D. (2006) Divisions of Labour: the Analysis of Parentheticals. Lingua: USM.

4. Dehe, N.; Kavalova, Y. (2007) Parentheticals. Amsterdam: John Benjamins.

5. Jigadlo, V.N.; Ivanova I.P.; Iofik, L.L. (1956) Sovremenniy angliyskiy yazyk. M.: Izd. Lit. na in.yaz.

6. Rudnev, A.G. (1959) Sintaksis oslojnyonnogo predlojeniy. M.: Academia.

7. Yartseva, V.N. (1961) Istoricheskiy syntaksis angliyskogo yazika. M.: Leningrad.

\section{Sources of Data:}

1. Aldington, R. (1958) Death of a Hero. M.: Khud. Lit.

2. Bronte, Ch. (1954) Jane Eyre. M.: Foreign Languages Publishing House.

3. Cronin, A.J. (1960) Hatter's Castle. M.: Foreign Languages Publishing House.

4. Dickens, Ch. (1951) Martin Chuzzlewit. Volumes I. Il. M.: Foreign Languages Publishing House.

5. Galsworthy, J. (1950) Man of Property. M.: Foreign Languages Publishing House.

6. Wells, H.G. (1914) Sir Isaak Harmon's Wife. London: Macmillan.

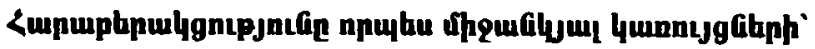

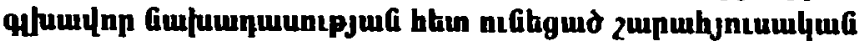

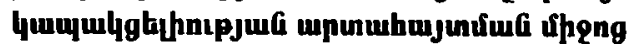

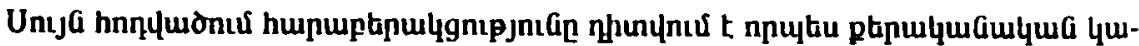

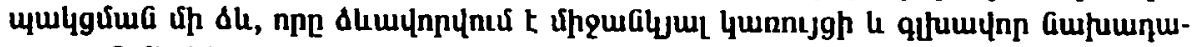

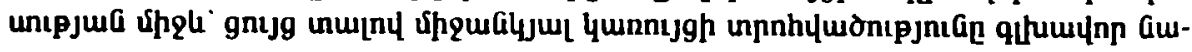




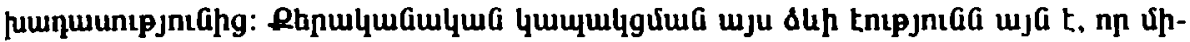

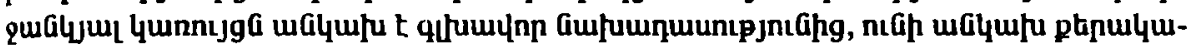

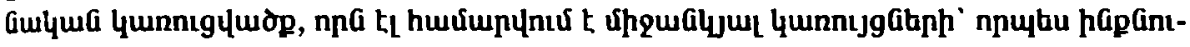

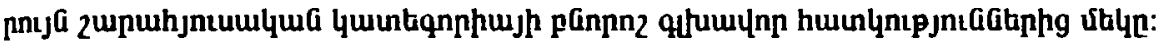

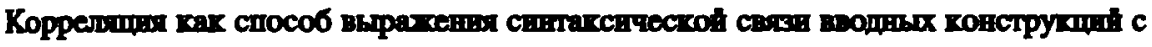

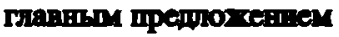

В данной статье корреляция рассматрквается как однн из способов грамматической связи, которая формируется между вводной конструкшией и главным предложением, показывая оттраничение вводной конструкции от главного предложения. Исследования показывают, что сущность этой грамматической связи заключается в том, чо вводная конструкция не завискма от главного предложения и имеет самостоятельную грамматнческую конструкцию, которая счнтается главной характерной чертой вводных конструкций как самостоятелыная синтаксическая категория. 